\title{
Incidence of community onset MRSA in Australia: least reported where it is Most prevalent
}

\author{
Jessica K. Cameron ${ }^{1 *}$ D, Lisa Hall ${ }^{1,2}$, Steven Y. C. Tong ${ }^{3,4}$, David L. Paterson ${ }^{5}$ and Kate Halton ${ }^{1}$
}

\begin{abstract}
Background: This is the first review of literature and synthesis of data on community onset methicillin resistant Staphylococcus aureus (CO-MRSA) infections in Australia. Incidence of CO-MRSA varies considerably in Australia, depending on geographic and demographic factors.
\end{abstract}

Methods: Data for the rates of MRSA infections were collected from articles identified using PubMed, Scopus, the grey literature and data from State and Federal Government Surveillance Systems. We synthesized data and developed a framework for how data was selected, collated, linked, organized and interpreted.

Results: The results of our literature search demonstrates considerable gaps in the reporting of CO-MRSA in Australia. Consequently, total incidences were under reported; however the available data suggests the incidence varied between 44 (Tasmania) and 388 (southern Northern Territory) cases per 100,000 person years. Hospitalised cases of COMRSA varied between 3.8 (regional Victoria) and 329 (southern Northern Territory). Taking the median percentage of infections by site for all regions available, skin and soft tissue infections (SSTIs) consisted of 56\% of hospitalized COMRSA, compared with bacteremias, which represented 14\%. No region had a complete data set of CO-MRSA infections treated in out-patient settings and so incidences were underestimates. Nevertheless, estimates of the incidence of COMRSA treated outside hospitals varied between 11.3 (Melbourne) and 285 (Northern Territory) per 100,000 person-years. These infections were chiefly SSTIs, although urinary tract infections were also noted.

Incidences of CO-MRSA blood-stream infections and outpatient skin and soft tissue infections have been increasing with time, except in Tasmania. CO-MRSA is observed to affect people living in remote areas and areas of socioeconomic disadvantage disproportionately.

Conclusions: We generated the first estimates of the incidence of CO-MRSA infections in Australia and identified stark regional differences in the nature and frequency of infections. Critically, we demonstrate that there has been a lack of consistency in reporting CO-MRSA and a general dearth of data. The only government in Australia that requires reporting of CO-MRSA is the Tasmanian, where the infection was least prevalent. Some regions of Australia have very high incidences of CO-MRSA. To improve surveillance and inform effective interventions, we recommend a standardized national reporting system in Australia that reports infections at a range of infection sites, has broad geographic coverage and consistent use of terminology. We have identified limitations in the available data that hinder understanding the prevalence of CO-MRSA.

Keywords: Staphylococcus aureus, Methicillin resistant Staphylococcus aureus, Community, Antimicrobial resistance, Australia

\footnotetext{
* Correspondence: jk.cameron@qut.edu.au

${ }^{1}$ Australian Centre for Health Services Innovation and the Institute for Health and Biomedical Innovation, Queensland University Technology, Brisbane,

Australia

Full list of author information is available at the end of the article
}

(C) The Author(s). 2019 Open Access This article is distributed under the terms of the Creative Commons Attribution 4.0 International License (http://creativecommons.org/licenses/by/4.0/), which permits unrestricted use, distribution, and reproduction in any medium, provided you give appropriate credit to the original author(s) and the source, provide a link to the Creative Commons license, and indicate if changes were made. The Creative Commons Public Domain Dedication waiver (http://creativecommons.org/publicdomain/zero/1.0/) applies to the data made available in this article, unless otherwise stated. 


\section{Background}

Staphylococcus aureus is carried asymptomatically by half (range 29-84\%) [1-4] the population and frequently causes minor skin infections.

Compared with methicillin-susceptible $S$. aureus infections, methicillin-resistant $S$. aureus (MRSA) infections have been associated with increased hospitalisation rates, [5] increased mortality [6, 7] and greater delays in receiving active antimicrobial therapy, [5, 8] resulting in poorer outcomes, including increased mortality and increased length of stay. [9-12]

Historically, MRSA has been associated with healthcare associated infections (HAI); however, broad-scale infection prevention efforts have reduced hospital onset (HO) HAI infections and the circulation of strains traditionally associated with healthcare. $[13,14]$ More recent evidence suggests most MRSA infections are now arising in the community. $[13,15]$ Rates of MRSA infections appear to be increasing $[14,16,17]$ faster than rates of growth of population [18] or healthcare utilisation. [14]

Community onset (CO-MRSA) infections are defined as cases either identified in a primary healthcare setting or are cases where symptoms were observed and a pathology sample positive for MRSA was collected within $48 \mathrm{~h}$ of hospitalisation. Compared to HAI MRSA, CO-MRSA infections have been associated with increased risk of metastatic seeding; decreased chance of empirical antimicrobials being effective and increased duration of antibacterial therapy. [19] CO-MRSA bloodstream infections (BSIs) are more likely to require admission to an intensive care unit. [19] Patients with CO-MRSA infections tend to be younger and often are otherwise healthy. $[19,20]$

The incidence of CO-MRSA infection across Australia has not been documented, but it is known to vary geographically. [7] Only in Tasmania is reporting of CO-MRSA mandatory. The Australian Group on Antimicrobial Resistance has regularly reported on the number of MRSA BSI cases from 32 institutions from each state and territory, with the most recent report specifying number of community onset cases. [21] Previous nation-wide studies have reported the incidence of $S$. aureus bacteremia $(\mathrm{SAB})$, estimating that in Australia, 61 to $77 \%$ of SABs were CO, $72 \%$ of MRSA SABs were $\mathrm{CO}$ and $13 \%$ of all SABs were CO-MRSA. [21, 22]

Hence, incidences of CO-MRSA infections cannot be calculated from currently available routinely reported data. International Classification of Diseases (ICD-10) diagnosis data has been found to be unreliable for such specific diagnoses, lacking sensitivity and having low positive predictive value for measuring the number of hospital acquired infections. [23-25] The Australian Institute of Health and Welfare (AIHW) recently released a report on SABs, but omitted location of onset and susceptibility to methicillin. [26]
We here generate the first estimate of the national incidence of CO-MRSA infections, by synthesizing data collated from academic literature and government reports. We identify regional differences in the nature and frequency of infection. We recommend changes in measurement and reporting to enable future assessment of key questions.

\section{Methods}

\section{Literature search}

The screening and selection process of the literature review is outlined in Fig. 1 and described in the Additional file 1.

We sought studies that published numbers of all infections in a defined region or population and time. We searched the academic literature between January 2000 and April 2016, using PubMed and Scopus and the terms "community" and "onset", "acquired" or "associated", combined with "methicillin resistant Staphylococcus aureus" and "Australia". Furthermore, we sought literature from State and Federal Government Health Department websites and consulted authors and specialists for grey literature.

We excluded clinical case studies and studies that excluded adults, did not include data from Australia, began before 2000, did not have a defined period of data collection, required consent from individual patients, or did not provide information on whether the infection onset occurred in hospital or in the community. If more than one data set was available for a region, we included those that excluded infections with healthcare associated risk factors, as defined by Kallen et al. [27]; or if two data sets used the same definitions for the same region, the most recent was included.

"Site" is used to refer to the anatomical site of an infection. "Region" or "area" refers to a geographic space to which a data set relates. "Location" refers to where the patient was at the time of onset of the infection.

\section{Study populations}

The data were analyzed for each state or territory. Northern Territory (NT) data arose from two sub regions: The Top End and the Alice Springs region, as shown by the dotted line in Fig. 2 and defined using the Statistical Local Areas from the Australian Bureau of Statistics (ABS) that best reflect the local health districts.

\section{Data synthesis}

Number of infections, denominator population and duration of data collection were required to estimate incidence. Where available, the specified catchment population was used as denominator population. Otherwise, the catchment population or area was sought from state health departments or hospital websites and ABS census data for that area and time period was used. 


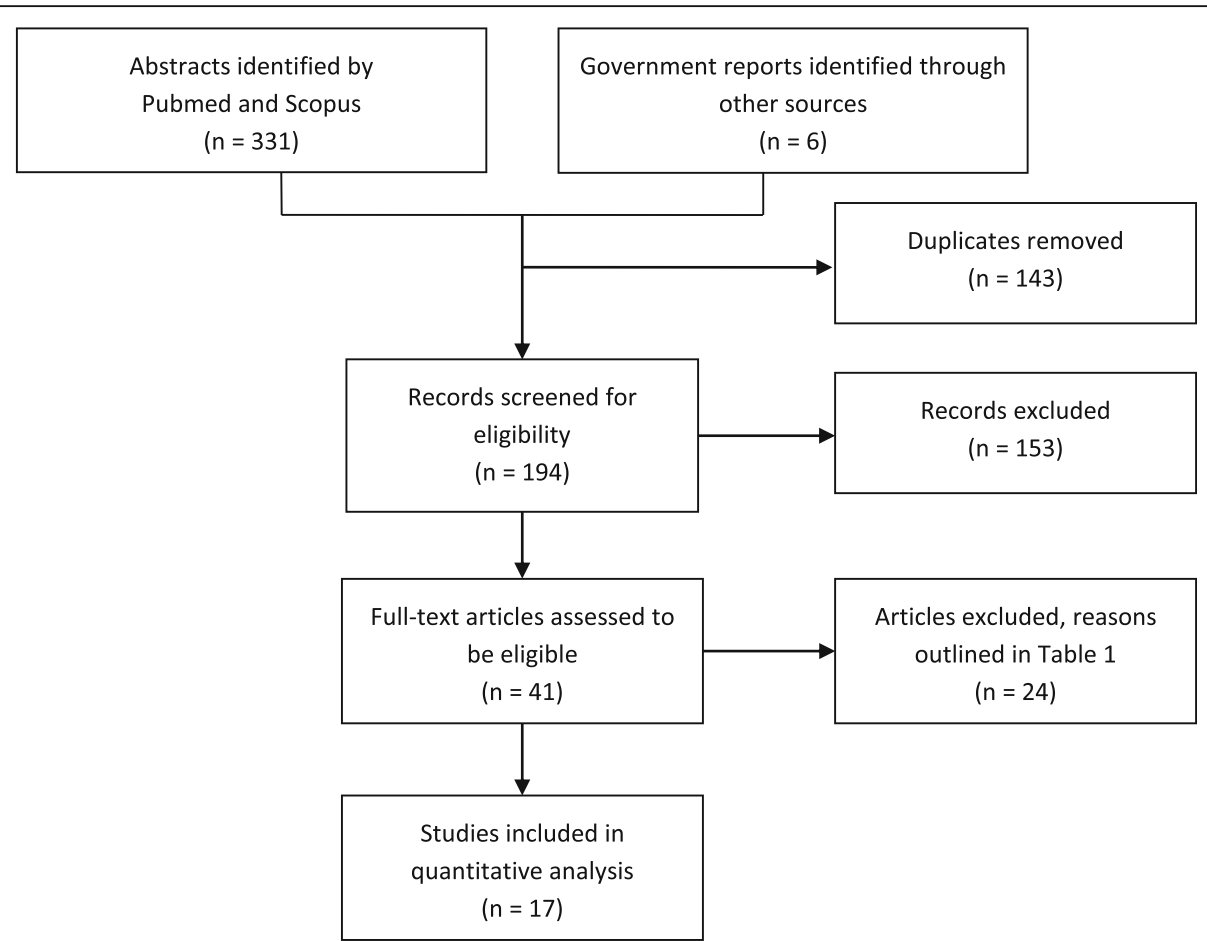

Fig. 1 Flow chart detailing the study screening and selection process

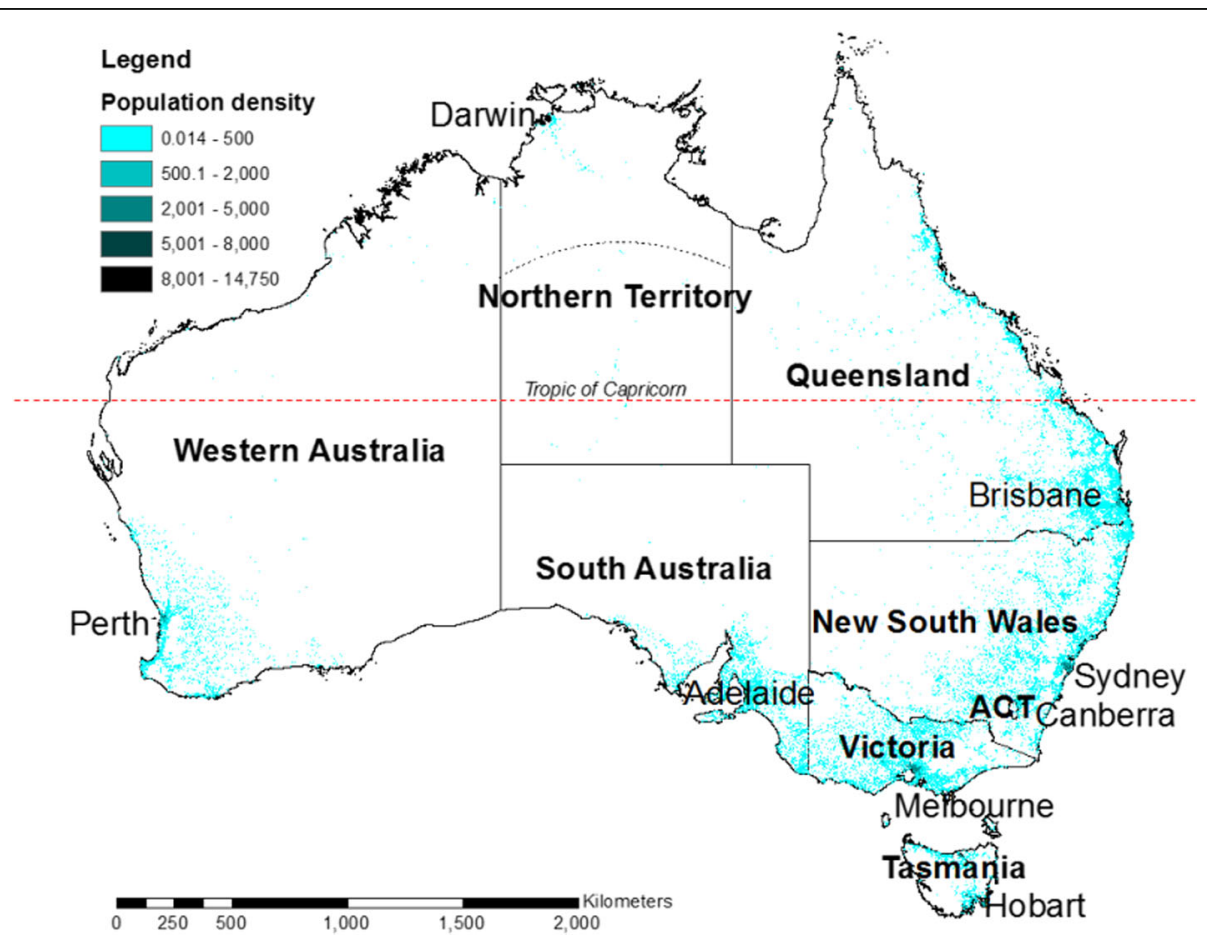

Fig. 2 Map of Australia showing the population density (from ABS); states and territories, capital cities and the Tropic of Capricorn 
Incidence of BSIs, lower respiratory tract (LRTI) and skin and soft tissue (SSTI) infections were calculated, generally using numbers of infections by site. Total incidences were calculated using total number of patients with an infection. Incidence for infections listed as "other", musculoskeletal, bone or joint, endocarditis or "of other sterile cavities" were not calculated because of lack of data, clarity or consistency of definitions between publications; however, these infections were included in the totals. The incidence of infections at these sites were expected to be considerably lower than that of SSTIs.

Incidence was calculated separately for cases treated as inpatients (IPs), outpatients (OPs) and at emergency departments (EDs). Where necessary, it was assumed that all BSIs and LRTIs were admitted, based on expert advice (personal communication: M. O'Sullivan, January 12, 2016; S. Tong, November 11, 2015 and G. Coombs, October 1, 2015).

\section{Results}

Literature search

All studies included in this review specified that the data represented clinically significant isolates and excluded screening swabs, duplicates and repeat cultures from the same patient within 14 days. In two publications, [13, 28] discharge diagnoses for some cases were indicative of a HAIand these cases were excluded.

$\mathrm{CO}$ infections were generally defined as an infection detected within $48 \mathrm{~h}$ of admission to hospital, using hospital records. Many studies also excluded patients with various healthcare associated risk factors from the definition of $\mathrm{CO}$ or indicated the number of cases of HAIs included as CO. $[19,20]$ Some publications excluded specific cases as noted in the footnotes to Table 1, below.

Few data were available on CO-MRSA by site of infection, as shown in Table 1, often because site-specific data included nosocomial cases. Criteria for diagnoses were seldom provided; however, one study identified pneumonia using radiographic evidence in addition to a positive culture of respiratory fluids or blood. [8] Generally, BSIs were identified by positive blood culture, with some studies requiring symptoms. [29] SSTIs were usually identified by type of pathology specimen. [14, 28] There was a wealth of data on BSIs, two studies specifically on LRTIs $[29,30]$ and one on infective endocarditis [31].

\section{Data synthesis - Incidence calculations}

Data used to estimate incidence was either: incidence of CO-MRSA, [18, 32, 33] numbers of CO-MRSA infections in a given period of time, [20,34-36] numbers of MRSA infections and proportions that were nosocomial or $\mathrm{CO}$, with and without HAI risk factors or, finally, the number of CO S. aureus infections and the proportion of those that were MRSA.

\section{Inpatient populations}

Total incidences and incidences for hospitalized CO-MRSA infections are presented in Table 2, with percentages of the populations who are Indigenous, who live in remote areas and who live in areas with an average Index of Relative Socioeconomic Disadvantage (IRSD) in the lowest decile in Australia, indicating socioeconomic disadvantage.

Table 2; Total incidence and incidence of hospitalized (IP) CO-MRSA infections by site of infection and for various regions, calculated using published numbers of infections over defined time periods.

Availability of data was highly regional, with ample data from the central and northern regions, a paucity of data from the most populous states of Victoria and New South Wales (NSW) and no publications from South Australia or regional Western Australia (WA), which neighbor regions of high incidence.

Data for BSIs was available for most state or territory capitals and three states, representing over half the population of Australia. Aside from BSIs, approximately a quarter of the population were represented by some form of data: either total CO-MRSA infections, total inpatient CO-MRSA infections or one of SSTIs or LRTIs.

BSIs that were secondary to SSTIs or LRTIs were included in Table 2 as both sites of infection, but only once in the total column. Many BSIs occurred simultaneously with infections of other sites not included in this analysis, such as bone and joint infections. Together, SSTIs, LRTIs and BSIs accounted for nearly all patients.

Incidence varied greatly by region. The Alice Springs region had the highest rates, with an incidence of inpatient SSTIs four times that of the Top End. The Top End had second highest rates, with incidences over three-fold that of its neighbor, Queensland. The southern-most regions of the ACT, Victoria and Tasmania experienced low incidences of CO-MRSA BSIs. The proportions of infection at each anatomical site in Queensland were similar to the proportions in Alice Springs.

Consistent with previous studies a higher incidence of CO-MRSA was observed for locations with a higher proportion of people identifying as Indigenous, those with more socio-economic disadvantage, and those living in more remote locations $[15,37,38]$.

\section{Outpatient populations}

The incidence of CO-MRSA infections that were not hospitalized is shown in Table 3. The sources of data on infections treated as outpatients were variously from private community pathology services, state coordinated pathology laboratories or a hospital pathology service.

Although limited, the outpatient data suggests similar geographical trends to those observed in inpatients; 
Table 1 Publications on CO-MRSA infections in Australia used to calculate incidences in this study

\begin{tabular}{|c|c|c|c|c|c|c|c|}
\hline Citation & Region $^{a}$ & $\begin{array}{l}\text { Data collection } \\
\text { period }\end{array}$ & $\begin{array}{l}\text { Admission } \\
\text { status }\end{array}$ & $\begin{array}{l}\text { Site of } \\
\text { infection }\end{array}$ & $\begin{array}{l}\text { Data } \\
\text { source }(s)^{c}\end{array}$ & $\begin{array}{l}\text { Additional } \\
\text { exclusions }^{\mathrm{d}}\end{array}$ & $\begin{array}{l}\text { Publication } \\
\text { type }\end{array}$ \\
\hline Nimmo 2013 [13] & Queensland & 2011 & $\mathrm{IP}, \mathrm{OP}, \mathrm{ED}$ & All & $P, D$ & $\mathrm{~T}$ & PRJ \\
\hline Stevens 2006 [28] & Alice Springs, NT & $2005-6$ & $\mathrm{IP}, \mathrm{OP}, \mathrm{ED}$ & All & $R, D$ & T & PRJ \\
\hline Agostino 2016 [20] & Hunter - New England, NSW & $2008-14$ & $\mathrm{IP}, \mathrm{OP}, \mathrm{ED}$ & Total & $\mathrm{R}$ & $\mathrm{T}$ & Th \\
\hline Mitchell 2009 [46] & Tasmania & $2008-9$ & $\mathrm{IP}, \mathrm{OP}, \mathrm{ED}$ & Total & S & $s, c, p, d, t$ & GR \\
\hline Tong 2009 [15] & Top End, NT & $2006-7$ & $\mathrm{IP}, \mathrm{ED}$ & Total & $P$ & t,Other & PRJ \\
\hline Wehrhahn 2010 [8] & Perth - Fremantle, WA & $2005-7$ & $\mathbb{I P}$ & All & $P$ & $s, c, p, d, o, t$ & PRJ \\
\hline Bennett 2007 [34] & Small hospitals Victoria & $2004-5$ & IP & Total & S & T & PRJ \\
\hline Marquess 2013 [35] & Queensland & 2005-2010 & IP & BSI & $\mathrm{R}$ & NS & PRJ \\
\hline Robinson 2009 [19] & Perth, WA & 1997-2007 & IP & BSI & $\mathrm{R}$ & t,Other & PRJ \\
\hline Laupland 2013 [33] & $\mathrm{ACT}$ & $2000-8$ & IP & BSI & NS & NS & PRJ \\
\hline Strachan 2014 [18] & Victoria & 2009-13 & IP & BSI & S & - & GR \\
\hline Wells 2014 [32] & Tasmania & 2008-14 & IP & BSI & S & $s, c, p, d, t$ & GR \\
\hline Tong 2015 [17] & Northern Territory & $2008-12$ & $\mathrm{OP}$ & SSTI & C & NS & PRJ \\
\hline Bennett 2014 [36] & Melbourne, Vic & 2006 & $\mathrm{OP}$ & SSTI & C & $L, t$ & PRJ \\
\hline Pandey 2008 [39] & Bowral, NSW & 2004 & ED & SSTI & NS & NS & LE \\
\hline Lim 2014 [40] & The Alfred Hospital, Vic & 2003-11 & ED & BSI & NS & $m, t$ & PRJ \\
\hline
\end{tabular}

${ }^{a}$ Australian Capital Territory (ACT), Victoria (Vic)

${ }^{b}$ All: data for SSTIs, LRTIs, BSIs and others listed separately, Total: only data for total infections were provided

${ }^{\mathrm{C}} \mathrm{R}$ : retrospective review of laboratory database, P: prospectively identified cases for inclusion, C: Community pathology database, S: surveillance system, D: discharge diagnosis, NS: not stated

d s: surgical procedure - some authors required that the infection was at the surgical site c: therapy for cancer (variously: receiving IV chemotherapy, being an oncology patient, neutropenia or immunosuppressive medication), p: percutaneous or indwelling device, d: dialysis, t: time since previous discharge (variously $\leq 48 \mathrm{~h}$ to $\leq 12$ months), L: residence in long term care facility, $\mathrm{m}$ : children (either less than 18 or 20 years old), o: other, NS: none stated. Further exclusion criteria included history of $S$. aureus infection, being an intravenous drug user, organ transplant recipients, respiratory and burns patients, receiving plasmapheresis, home IV therapy or employment in healthcare

e $P R J$ peer-reviewed academic article, Th thesis, GR government report, $L E$ letter to the editor

specifically: high incidence in NT and Alice Springs, moderate in Queensland and relatively low in Melbourne and Tasmania. Most outpatient CO-MRSA cases detected were SSTIs.

\section{Emergency department}

All presentations of MRSA to ED were considered CO. Only three papers offered data on presentations of MRSA to emergency departments. In regional NSW in 2004, the incidence of CO-MRSA in skin abscesses presenting to ED was 80 / 100,000 person-years. [39] At The Alfred Hospital in Melbourne between 2003 and 2011, the average incidence was 0.6 / 100,000 person-years. [40] The incidence of CO-MRSA presenting to ED in the Top End was 29 / 100,000 person-years in 2006-7. [15] This estimate required the assumption that all nosocomial cases and colonizations detected were included in the percentage reported as hospitalizations. It was also assumed that those not hospitalized had presented to ED.

\section{Pathways to seek care}

Methicillin resistance is only identifiable by pathology services and so all data used were from or linked to pathology databases. The multiplicity of care-seeking behaviors resulted in some patients' infections being detected by a pathology service that did not reflect their admission status or being registered by more than one pathology laboratory. Some data coming from hospital pathology laboratories are from patients presenting to and receiving treatment in primary care. Similarly, some patients whose infections were identified by community pathology services were admitted.

Assuming all BSIs are hospitalized, slightly less than half of all CO-MRSA BSIs in Melbourne initially presented to ED, based on the incidences above.

\section{Incidence over time}

Some incidence data were available for multiple time points. A study by Tong and colleagues [17] gave outpatient incidences at multiple time points in NT (S. Tong, personal communication, January 20, 2016), as shown in Fig. 3. Figure 4 presents the incidence at different time points of BSIs in Queensland, [13, 14, 35] Victoria, [18] and Tasmania [32]. Additionally, the incidence of all CO-MRSA infections in Tasmania increased from 39 in 2008 to 49 /100000 person-years in 2009. Except for BSIs in Tasmania, there appears to be an increasing trend with time in the incidence of CO-MRSA infections, both in inpatient and outpatient cases. 
Table 2 Incidence of hospitalized (IP) CO-MRSA infections by site of infection and for various regions, calculated using published numbers of infections over defined time periods

\begin{tabular}{|c|c|c|c|c|c|c|c|c|c|c|c|}
\hline \multirow[t]{2}{*}{ Region } & \multirow{2}{*}{$\begin{array}{l}\text { Population size } \\
\text { used in } \\
\text { calculations }\end{array}$} & \multirow{2}{*}{$\begin{array}{l}\text { Data collection } \\
\text { period }\end{array}$} & \multicolumn{5}{|c|}{ Incidence (/100000 person-years) } & \multirow[t]{2}{*}{ References } & \multicolumn{3}{|c|}{ Demographic factors } \\
\hline & & & Total & Total IP & IP SSTI & LRTI & $\begin{array}{l}\mathrm{BSI} \\
\left(1^{\circ} \text { and } 2^{\circ}\right)\end{array}$ & & $\begin{array}{l}\% \\
\text { Indigenous [47] }\end{array}$ & $\begin{array}{l}\% \text { Living in } \\
\text { remote } \\
\text { areas [48] }\end{array}$ & $\begin{array}{l}\text { \% Living in } \\
\text { area with } \\
\text { lowest IRSD } \\
\text { decile [49] }\end{array}$ \\
\hline Top End & $176,000[15]$ & $2006-7$ & & 81 & & & & [15] & 26 & 28 & 20 \\
\hline Queensland & $4,500,000[13]$ & $2005-11$ & 95.5 & 26 & 22.8 & 2.8 & 3.7 & {$[13,35]$} & 4 & 3 & 9 \\
\hline $\begin{array}{l}\text { Alice } \\
\text { Springs }\end{array}$ & $51,000[28]$ & $2005-6,14$ & 388 & 329 & 184 & 31 & 20 & {$[28,50]$} & 43 & 100 & 33 \\
\hline $\begin{array}{l}\text { Hunter - } \\
\text { New England }\end{array}$ & $752,952[20,51]$ & $2008-14$ & 146 & & & & & {$[20,52]$} & 5 & 0.3 & 11 \\
\hline $\begin{array}{l}\text { Perth - } \\
\text { Fremantle }\end{array}$ & $470,389[53,54]$ & 1997-2007 & & 6.1 & 2.1 & 1.1 & 4.2 & {$[8,19]$} & 2 & 0.02 & 2 \\
\hline $\mathrm{ACT}$ & $370,000[33]$ & $2000-8$ & & & & & 2 & [33] & 2 & 0 & 1 \\
\hline $\begin{array}{l}\text { Regional } \\
\text { Victoria }\end{array}$ & $617,692[55]$ & $2004-5$ & & 3.8 & & & & {$[18,46]$} & 2 & 0.4 & 11 \\
\hline Victoria & NS & 2009-13 & & & & & $>1.6$ & [18] & 1 & 0.1 & 9 \\
\hline Tasmania & $489,958[55,56]$ & 2008-14 & 44 & & & & 1 & {$[32,46]$} & 4 & 2 & 17 \\
\hline
\end{tabular}

\section{Discussion}

Incidence of CO-MRSA in parts of Australia is comparatively high. In 2011, a cross-section of localities in the United States had adjusted incidences of CO-MRSA of 5.3 (total) and 4.8 (inpatient) per 100,000 person-years. [41] The definitions of CO and HAI used in the US study more closely resembled that of the Perth-Fremantle study, where rates were lower. However, in the US study, the total incidence of all $\mathrm{CO}$, with and without healthcare associated risk factors, both crude and adjusted was comparable to Queensland, which excluded patients with the key HAI risk factors, and was much lower than the NT rates. Laupland and colleagues [33] found that in the period 2005-2008, various regions in Scandinavia and Canada had adjusted incidences of CO-MRSA BSIs of, respectively, less than 0.3 and between 1.8 and 5.4 infections per 100,000 person-years, while the ACT had an adjusted incidence of 2 per 100,000 person-years, which was amongst Australia's lowest.

\section{Data synthesis}

Geographical differences are consistent with previous reports of MRSA, both $\mathrm{HO}$ and generally. [14, 16] The higher rates have been associated with ethnicity, remoteness and socio-economic status. [15, 37, 38]

Health system structure and availability and care-seeking behaviors may explain differences in incidence between regions. Alice Springs experienced considerably higher inpatient incidence than the Top End, possibly because access to outpatient care was limited for patients who lived remotely in southern NT. This may also account for the considerably higher incidence of CO-MRSA SSTIs presenting to ED in rural NSW compared with the incidence of all CO-MRSA presenting to ED in the Top End.

Most CO-MRSA infections were not admitted to hospital. In Queensland, the outpatient data were incomplete, nevertheless the outpatient incidence was 2.5 times that of inpatient incidence. Uniquely, a publication from Tasmania captured all CO-MRSA infections in the state - but did not distinguish whether cases were admitted or not. If, however, we assume that the ratio of BSIs to total inpatient infections in Tasmania was the same as in Queensland, then the incidence of outpatient CO-MRSA was 4.5-fold that of inpatient CO-MRSA.

Essentially all CO-MRSA treated as outpatients were SSTIs and a significant majority of admitted cases were

Table 3 Incidence of CO-MRSA infections treated as outpatients not presenting to an emergency department, by site of infection and for various regions, calculated using published numbers of infections over defined time periods

\begin{tabular}{|c|c|c|c|c|c|c|c|}
\hline \multirow[t]{2}{*}{ Region } & \multirow{2}{*}{$\begin{array}{l}\text { Population size } \\
\text { used in calculations }\end{array}$} & \multirow{2}{*}{$\begin{array}{l}\text { Data collection } \\
\text { period }\end{array}$} & \multirow{2}{*}{$\begin{array}{l}\text { Data } \\
\text { source }\end{array}$} & \multicolumn{3}{|c|}{ Incidence (/100000 person-years) } & \multirow[t]{2}{*}{ References } \\
\hline & & & & Total & SSTI & UTI & \\
\hline Northern Territory & $211,945[51]$ & $2008-12$ & Community & 285 & & & {$[17]$} \\
\hline Queensland & $4,500,000[13]$ & 2011 & State & & 64.5 & & [13] \\
\hline Alice Springs & $51,000[28]$ & $2005-6$ & Hospital & 145 & 141 & 4 & {$[28]$} \\
\hline Melbourne & $1,796,296[56]$ & 2006 & Community & 11.3 & 10.8 & & {$[36]$} \\
\hline
\end{tabular}




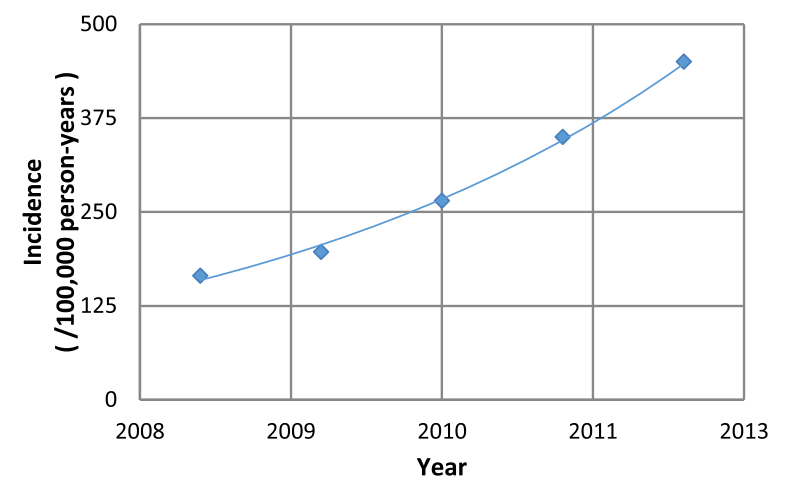

Fig. 3 Incidence of CO-MRSA SSTIs collected by a community pathology service provider in NT (personal communication, S. Tong January 20, 2016). [17]

SSTIs, except in Perth. This suggests that surveillance of CO-MRSA SSTIs is warranted. The incidence of LRTIs relative to BSIs varied by location, perhaps because different criteria were used to identify infections or difficulties in collecting pathology samples.

$\mathrm{CO}$ is now defined by the Centers for Disease Control as infections that occur within $72 \mathrm{~h}$ of admission; however, only one of the studies met this definition.

\section{Limitations}

There was a paucity of data in the academic literature, particularly on key indicators of morbidity such as site of infection and admission status. Lack of specificity in reporting $\mathrm{CO}$ infections has resulted in the inclusion of community onset infections both with and without healthcare associated risk factors in the data used to calculate incidences. Most publications lacked a breakdown of the number of infections by anatomical site. Given the difficulty of obtaining pathology specimens from patients with LRTIs, the number of cases of CO-MRSA LRTIs was probably a significant underestimate. For SSTIs, data were available for the absolute number of MRSA isolations. However, the denominator number of tests was typically

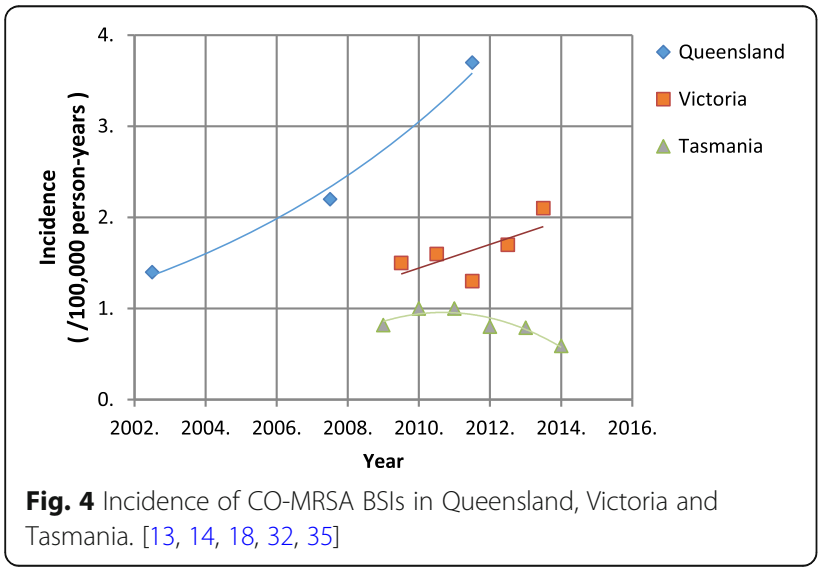

not reported or available and hence it is not clear the degree to which changes in the incidence of isolation of MRSA is related to changes in testing practices.

\section{Data sources}

Most studies used data from pathology departments of public hospitals; however, a key indicator of a patient's morbidity is whether they were ultimately admitted to hospital, $[8,39,40,42]$ which is not included in most pathology data sets. Therefore, to determine final admission status, pathology data needs to be linked to hospital records. Alternatively, assumptions can be used to estimate the proportion of cases of SSTIs and urinary tract infections (UTIs) that were hospitalized. In Queensland, patients' admission status at the time a positive pathology sample was collected was used as a proxy for whether an SSTI case was hospitalized, thus overestimating the proportion of outpatients and underestimating inpatients.

As the community clinic system is multifarious and multiple private pathology services exist, no study captured all and only cases that were treated in the community. The multiple pathology services mean that, except in Tasmania, the ED and outpatient data reported were incomplete and underestimated the burden, leaving most infections unrepresented by the available data.

\section{Recommendations}

To understand the true burden of CO-MRSA, a national reporting system is required. Surveillance ought to be geographically comprehensive, since populations with highest prevalence are often the most difficult to survey, being remote and small in size. [43] Cases treated in primary care settings need to be captured as a large proportion of infections are not admitted to hospital. Currently available data focusses on BSIs; data collection needs to take in different infection sites and types to fully recognize the burden of disease. Finally, all information should be shared and available for analysis. In many states, HO or HAI MRSA is notifiable, suggesting that $\mathrm{CO}$ cases presenting at hospitals must be vetted for location of onset. This vetting process produces valuable information on $\mathrm{CO}$ infections that is not utilized currently.

Consistent terminology would also be advantageous. "Community-associated strains" continues to be used, although these strains are no longer associated with community acquisition $[6,14,15,44]$ and international recognition that it is inaccurate terminology. [45] The terms "multiresistant" and "non-multiresistant MRSA strains" are widely understood and highlight the significance of these strains.

\section{Conclusions}

We identified a paucity of data, a lack of consistency of definitions and highly regionalized data collection, 
resulting in an absence of information on the prevalence of CO-MRSA in populations where it is expected to be highest. Data on the most prevalent type of infection, SSTIs, were sparse, particularly in outpatient settings.

Reported incidence of CO-MRSA was high compared to other, demographically similar countries. Consistent, nationwide reporting of CO-MRSA cases is necessary to understand its true incidence and plan control strategies.

We recommend requirements for reporting MRSA, including the reporting of a wider range of infection sites, better geographic coverage and consistent use of terminology.

\section{Additional file}

Additional file 1: Further information on the literature identified and exclusions. (DOCX $21 \mathrm{~kb}$ )

\begin{abstract}
Abbreviations
ABS: Australian Bureau of Statistics; AlHW: Australian Institute of Health and Welfare; BSI: Blood stream infection; CO: Community-onset; CO-

MRSA: Community onset Methicillin Resistant Staphylococcus aureus; ED: Emergency department; GP: General practice; HAl: Healthcare associated infection; HO: Hospital onset; ICD-10: International Classification of Diseases; IP: Inpatients; IRSD: Index of Relative Socioeconomic Disadvantage; LRTI: Lower respiratory tract infection; MRSA: Methicillin Resistant Staphylococcus aureus; NSW: New South Wales; NT: Northern Territory; OP: Outpatient; S. aureus: Staphylococcus aureus; SAB: S. aureus bacteremia; SSTI: Skin and soft tissue infection; UTI: Urinary tract infection; WA: Western Australia
\end{abstract}

\section{Acknowledgements}

The authors wish to acknowledge the helpful conservations and technical assistance of Catherine Bennett, Geoff Coombs, Brett Mitchell, John Ferguson, Matthew O'Sullivan, Janet Strachan, Alistair McGregor and the Tasmanian Infection Prevention and Control Unit, Teresa Wozniak and Louise Barnsby.

\section{Funding}

This research was supported by NHMRC grant GNT1027589. The NHMRC played no role in the design of the study; nor collection, analysis, and interpretation of data; nor in writing the manuscript. SYCT is a NHMRC Career Development Fellow (\#1145033).

\section{Availability of data and materials}

All data generated or analysed during this study are included in this published article, the cited references and the associated supplementary information files.

\section{Authors' contributions}

$\mathrm{KH}$ conceived the idea for the review. JKC analyzed and interpreted the literature with assistance from KH and LH. JKC wrote the manuscript with assistance in editing from KH, SYCT and LH. DLP and SYTC provided important intellectual content. All authors read and approved the final manuscript.

\section{Ethics approval and consent to participate}

Not applicable.

\section{Consent for publication}

Not applicable.

\section{Competing interests}

The authors declare that they have no competing interests.

\section{Publisher's Note}

Springer Nature remains neutral with regard to jurisdictional claims in published maps and institutional affiliations.

\section{Author details}

${ }^{1}$ Australian Centre for Health Services Innovation and the Institute for Health and Biomedical Innovation, Queensland University Technology, Brisbane, Australia. ${ }^{2}$ School of Public Health, University of Queensland, Brisbane, Australia. ${ }^{3}$ Victorian Infectious Disease Service, The Royal Melbourne Hospital, and Doherty Department University of Melbourne, Peter Doherty Institute for Infection and Immunity, Victoria, Australia. ${ }^{4}$ Menzies School of Health Research, Darwin, Australia. ${ }^{5} \cup Q$ Centre for Clinical Research, University of Queensland, Brisbane, Australia.

Received: 24 October 2018 Accepted: 1 February 2019

Published online: 12 February 2019

References

1. Amir LH, Garland SM, Lumley J. A case-control study of mastitis: nasal carriage of Staphylococcus aureus. BMC Fam Pract. 2006;7(1):57.

2. Munckhof WJ, Nimmo GR, Schooneveldt JM, Schlebusch S, Stephens AJ, Williams G, et al. Nasal carriage of Staphylococcus aureus, including community-associated methicillin-resistant strains, in Queensland adults. Clin Microbiol Infect. 2009;15(2):149-55.

3. Stubbs E, Pegler M, Vickery A, Harbour C. Nasal carriage of Staphylococcus aureus in Australian (pre-clinical and clinical) medical students. J Hosp Infect. 1994;27(2):127-34.

4. Wertheim HFL, Melles DC, Vos MC, van Leeuwen W, van Belkum A, Verbrugh HA, et al. The role of nasal carriage in Staphylococcus aureus infections. Lancet Infect Dis. 2005;5(12):751-62.

5. Turnidge JD, Kotsanas D, Munckhof W, Roberts S, Bennett CM, Nimmo GR, et al. Staphylococcus aureus bacteraemia: a major cause of mortality in Australia and New Zealand. Med J Aust. 2009;191(7):368-73.

6. Munckhof WJ, Nimmo GR, Carney J, Schooneveldt JM, Huygens F, InmanBamber J, et al. Methicillin-susceptible, non-multiresistant methicillinresistant and multiresistant methicillin-resistant Staphylococcus aureus infections: a clinical, epidemiological and microbiological comparative study. Eur J Clin Microbiol Infect Dis. 2008;27(5):355-64.

7. Nimmo GR, Coombs GW. Community-associated methicillin-resistant Staphylococcus aureus (MRSA) in Australia. Int J Antimicrob Agents. 2008; 31(5):401-10.

8. Wehrhahn MC, Robinson JO, Pearson JC, O'Brien FG, Tan HL, Coombs GW, et al. Clinical and laboratory features of invasive community-onset methicillin-resistant Staphylococcus aureus infection: a prospective casecontrol study. Eur J Clin Microbiol Infect Dis. 2010;29(8):1025-33.

9. Ibrahim EH, Sherman G, Ward S, Fraser VJ, Kollef MH. The influence of inadequate antimicrobial treatment of bloodstream infections on patient outcomes in the ICU setting. Chest. 2000;1 18(1):146-55.

10. Khatib R, Saeed S, Sharma M, Riederer K, Fakih MG, Johnson LB. Impact of initial antibiotic choice and delayed appropriate treatment on the outcome of Staphylococcus aureus bacteremia. Eur J Clin Microbiol Infect Dis. 2006; 25(3):181-5.

11. Leibovici L, Shraga I, Drucker M, Konigsberger H, Samra Z, Pitlik SD, et al. The benefit of appropriate empirical antibiotic treatment in patients with bloodstream infection. J Int Med. 1998;244(5):379-86.

12. Lodise TP, McKinnon PS, Swiderski L, Rybak MJ. Outcomes analysis of delayed antibiotic treatment for hospital-acquired Staphylococcus aureus bacteremia. Clin Infect Dis. 2003;36(11):1418-23.

13. Nimmo GR, Bergh H, Nakos J, Whiley D, Marquess J, Huygens F, et al. Replacement of healthcare-associated MRSA by community-associated MRSA in Queensland: confirmation by genotyping. J Inf Secur. 2013;67(5): 439-47.

14. Nimmo GR, Fong J, Paterson DL, McLaws ML. Changing epidemiology of meticillin-resistant S. aureus in Queensland, Australia, 2000-2006: use of passive surveillance of susceptibility phenotypes. J Hosp Infect. 2008;70(4): 305-13.

15. Tong SY, Bishop EJ, Lilliebridge RA, Cheng AC, Spasova-Penkova Z, Holt DC, et al. Community-associated strains of methicillin-resistant Staphylococcus aureus and methicillin-susceptible $S$. aureus in indigenous northern Australia: epidemiology and outcomes. J Infect Dis. 2009;199(10):1461-70.

16. Coombs G, Pearson J, Robinson O. Western Australian methicillin-resistant Staphylococcus aureus (MRSA) epidemiology and typing report. Perth: Western Australia Department of Health; 2015

17. Tong SY, Varrone L, Chatfield MD, Beaman M, Giffard PM. Progressive increase in community-associated methicillin-resistant Staphylococcus 
aureus in indigenous populations in northern Australia from 1993 to 2012 Epidemiol Infect. 2015;143(7):1519-23.

18. Strachan J, Easton M. Staphylococcus aureus bloodstream and cerebrospinal fluid infections in Victoria, 2009-2013. Melbourne: In Vic Infect Dis Bull; 2014.

19. Robinson JO, Pearson JC, Christiansen KJ, Coombs GW, Murray RJ. Community-associated versus healthcare-associated methicillin-resistant Staphylococcus aureus bacteraemia: a 10-year retrospective review. Eur J Clin Microbiol Infect Dis. 2009;28(4):353-61.

20. Agostino J. Utilising data for a better understanding of disease. Canberra: Australian National University; 2016

21. Coombs GW, Daley DA, Lee YT, Pang S. Australian group on antimicrobial resistance (AGAR) Australian Staphylococcus aureus Sepsis outcome Programme (ASSOP) annual report 2016. Commun Dis Intell (2018). 2018:42.

22. Williamson DA, Coombs GW, Nimmo GR. Staphylococcus aureus 'Down Under': contemporary epidemiology of S. aureus in Australia, New Zealand, and the south West Pacific. Clin Microbiol Infect. 2014:20(7):597-604.

23. Jones G, Taright N, Boelle PY, Marty J, Lalande V, Eckert C, et al. Accuracy of ICD-10 codes for surveillance of clostridium difficile infections, France. Emerg Infect Dis. 2012;18(6):979-81.

24. van Mourik MSM, van Duijn PJ, Moons KGM, Bonten MJM, Lee GM. Accuracy of administrative data for surveillance of healthcare-associated infections: a systematic review. BMJ Open. 2015;5(8):e008424.

25. Hargreaves J, Kok J. Australian hospital morbidity data on antibiotic resistance. Commun Dis Intell. 2003;27(Suppl):S55-60.

26. Australian Institute of Health and Welfare. Staphylococcus aureus bacteraemia in Australian public hospitals, in Health Servies Series. Canberra, ACT: AlHW; 2013.

27. Kallen AJ, Mu Y, Bulens S, Reingold A, Petit S, Gershman K, et al. Health careassociated invasive MRSA infections, 2005-2008. JAMA. 2010;304(6):641-8.

28. Stevens CL, Ralph A, McLeod JE, McDonald MI. Community-acquired methicillin-resistant Staphylococcus aureus in Central Australia. Commun Dis Intell. 2006;30(4):462-6.

29. Thomas R, Ferguson J, Coombs G, Gibson PG. Community-acquired methicillin-resistant Staphylococcus aureus pneumonia: a clinical audit. Respirology (Carlton, Vic). 2011;16(6):926-31.

30. Rémond MGW, Ralph AP, Brady SJ, Martin J, Tikoft E, Maguire GP. Community-acquired pneumonia in the central desert and north-western tropics of Australia. Int Med J. 2010;40(1):37-44.

31. Sy RW, Kritharides L. Health care exposure and age in infective endocarditis: results of a contemporary population-based profile of 1536 patients in Australia. Eur Heart J. 2010;31(15):1890-7.

32. Wells A, Wilson F, McGregor A, Mitchell B. Tasmanian acute public hospitals healthcare associated infection surveillance report. Hobart: Department of Health and Human Services; 2014

33. Laupland KB, Lyytikainen O, Sogaard M, Kennedy KJ, Knudsen JD, Ostergaard C, et al. The changing epidemiology of Staphylococcus aureus bloodstream infection: a multinational population-based surveillance study. Clin Microbiol Infect. 2013;19(5):465-71.

34. Bennett NJ, Bull AL, Dunt DR, Gurrin LC, Spelman DW, Russo PL, et al. MRSA infections in smaller hospitals, Victoria, Australia. Am J Infect Control. 2007; 35(10):697-9.

35. Marquess J, Hu W, Nimmo GR, Clements AC. Spatial analysis of communityonset Staphylococcus aureus bacteremia in Queensland, Australia. Infect Control Hosp Epidemiol. 2013;34(3):291-8.

36. Bennett CM, Coombs GW, Wood GM, Howden BP, Johnson LE, White D, et al. Community-onset Staphylococcus aureus infections presenting to general practices in South-Eastern Australia. Epidemiol Infect. 2014;142(3):501-11.

37. Engelman D, Hofer A, Davis JS, Carapetis JR, Baird RW, Giffard PM, et al. Invasive Staphylococcus aureus infections in children in tropical northern Australia. J Ped Infecti Dis Soc. 2014;3(4):304-11.

38. Tong SY, van Hal SJ, Einsiedel L, Currie BJ, Turnidge JD. Impact of ethnicity and socio-economic status on Staphylococcus aureus bacteremia incidence and mortality: a heavy burden in indigenous Australians. BMC Infect Dis. 2012;12:249.

39. Pandey R. Emergence of non-multiresistant methicillin-resistant Staphylococcus aureus as the commonest pathogen causing skin infections in a rural Australian city. J Inf Secur. 2008;56(5):393-4.

40. Lim CJ, Cheng AC, Kong DC, Peleg AY. Community-onset bloodstream infection with multidrug-resistant organisms: a matched case-control study. BMC Infect Dis. 2014;14:126.
41. Dantes R, Mu Y, Belflower R, Aragon D, Dumyati G, Harrison LH, et al. National burden of invasive methicillin-resistant Staphylococcus aureus infections, United States, 2011. JAMA Int Med. 2013;173(21):1970-8.

42. Aung AK, Skinner MJ, Lee FJ, Cheng AC. Changing epidemiology of bloodstream infection pathogens over time in adult non-specialty patients at an Australian tertiary hospital. Commun Dis Intell. 2012;36(4):E333-41.

43. Douglas MW, Lum G, Roy J, Fisher DA, Anstey NM, Currie BJ. Epidemiology of community-acquired and nosocomial bloodstream infections in tropical Australia: a 12-month prospective study. Tropical Med Int Health. 2004;9(7): 795-804.

44. Coombs GW, Nimmo GR, Daly DA, Le TT, Pearson JC, Tan HL, et al. Australian Staphylococcus aureus Sepsis outcome Programme annual report, 2013. Commun Dis Intell Q Rep. 2014;38(4):E309-19.

45. Chua K, Laurent F, Coombs G, Grayson ML, Howden BP. Antimicrobial resistance: not community-associated methicillin-resistant Staphylococcus aureus (CA-MRSA)! A clinician's guide to community MRSA - its evolving antimicrobial resistance and implications for therapy. Clin Infect Dis. 2011; 52(1):99.

46. Mitchell B, McGregor A, Brown S, Wells A. Tasmanian acute public hospitals healthcare associated infection surveillance report. Hobart: Department of Health and Human Services; 2009.

47. Australian Bureau of Statistics Indigenous Status (May 2017), TableBuilder. 2011; Available from: ABS TableBuilder data.

48. Australian Bureau of Statistics Remoteness Areas (May 2017), TableBuilder. 2011; Available from: ABS TableBuilder data.

49. Australian Bureau of Statistics. Socio-Economic Indexes For Areas (May 2017), TableBuilder. 2013; 2033.0.55.001 - Census of Population and Housing: Socio-Economic Indexes for Areas (SEIFA), Australia, 2011; Available from: ABS TableBuilder data.

50. MacMorran E, Harch S, Athan E, Lane S, Tong S, Crawford L, et al. The rise of methicillin resistant Staphylococcus aureus: now the dominant cause of skin and soft tissue infection in Central Australia. Epidemiol Infect. 2017;145(13): 2817-26.

51. Australian Bureau of Statistics. Census data. 2011 [Accessed 08 March 2016]; Available from: <http://abs.gov.au/websitedbs/censushome.nsf/home/data>

52. Agostino JW, Ferguson JK, Eastwood K, Kirk MD. The increasing importance of community-acquired methicillin-resistant Staphylococcus aureus infections. Med J Aust. 2017;207(9):388-93.

53. South Metropolitan Health Service, Royal Perth Group Clinical Services Plan 2012-2015, Department of Health, Editor. 2012, Government of Western Australia: Perth, WA.

54. South Metropolitan Health Service, Fremantle Hospital and Health Service Clinical Services Plan 2012-2015, Department of Health, Editor. 2012, Government of Western Australia: Perth, WA.

55. Australian Bureau of Statistics. Census data. 2001 [Accessed 08 March 2016]; Available from: <http://abs.gov.au/websitedbs/censushome.nsf/home/data>

56. Australian Bureau of Statistics. Census data. 2006 [Accessed 08 March 2016]; Available from: <http://abs.gov.au/websitedbs/censushome.nsf/home/data>.

\section{Ready to submit your research? Choose BMC and benefit from:}

- fast, convenient online submission

- thorough peer review by experienced researchers in your field

- rapid publication on acceptance

- support for research data, including large and complex data types

- gold Open Access which fosters wider collaboration and increased citations

- maximum visibility for your research: over $100 \mathrm{M}$ website views per year

At BMC, research is always in progress.

Learn more biomedcentral.com/submissions 